\title{
VIEWING LATINA IMMIGRANT MOTHERS IN ASTURIAS, SPAIN, THROUGH AN EXISTENTIAL PSYCHOLOGY LENS
}

\author{
ELIZABETH BERROCAL
}

University of Oviedo, Oviedo, Asturias, Spain

(c) 2020 Elizabeth Berrocal

This is an open access article distributed under the Creative Commons Attribution-NonCommercial-NoDerivs license (http://creativecommons.org/licenses/by-nc-nd/3.0/)

DOI: $10.1515 /$ eras-2020-0001

\begin{abstract}
This paper reports the results of using an existential psychology perspective to examine interview responses of 13 Latina mothers who had immigrated to the Asturias region of Spain. Purposes of the interviews included determining the Latinas' reasons for immigrating. their post-migration challenges, and their responses to those challenges. Thematic analysis of the Latinas' answers to interview questions revealed that their deciding to migrate to Spain and their responses to post-migration challenges can be understood in terms of the key existential psychology concepts of free choice and meaning. The analysis revealed two self-identifications that provided the Latinas with life meaning that helped them deal with challenges: Being a Mother and Determination to Move Forward. It is argued that the presence of these two meanings in the Latinas' experiences provided them with a sense of coherence, purpose, and significance and helps account for the women's strength and resilience in the face of post-immigration economic, social, and personal challenges and for their choosing to remain in Spain despite those challenges.
\end{abstract}

\section{Keywords}

Latina, Spain, migration, existential psychology, life meaning, motherhood

\section{Introduction}

In the fall of 2017, 13 Latina immigrant mothers living in the principality of Asturias, northern Spain, sat for interviews. The purpose of the interviews was to learn the Latinas' reasons for immigrating from their original homes in Latin America, the degree to which they had retained or changed their gender-related self-identifications since immigrating, the reasons for their birth decisions, the challenges they had encountered since immigrating, and their responses to those challenges. The interviewees were from six different countries in South America and the Caribbean (Brazil, Colombia, Dominican Republic, Ecuador, Guatemala, and Peru), ranged in age from 20 to 40 years, and had been living in Spain for a few months to over 10 years. At the time of the interviews, all were either pregnant, had one or more children, or both. Interview questions inquired about several topics, including the Latinas' reasons for immigrating, their perceptions of women's roles in the home country compared to Spain, family and financial situations, views of being a mother, and attitudes toward their new home.

The Latinas' responses to interview questions painted a picture of a diverse group of individuals who had immigrated to Spain for various reasons, had encountered a number of challenges since their arrival, and had strong views about gender roles and being a mother. Several theoretical frameworks were employed to provide perspectives on the Latinas' responses, including symbolic interactionism and identity theory. These frameworks enabled a degree of understanding of factors that may have played a part in the Latinas' immigration 
experiences from a social psychology standpoint. To help provide further insights into the Latinas' experiences, their interview responses were also examined from an existential psychology perspective, which was deemed to be valuable for comprehending the immigrant Latinas' experiences from a personal standpoint. This paper focuses on how viewing the Latinas' reports from an existential psychology stance helps enhance understanding of the Latinas' experiences. Though clearly, many of those experiences are conditioned by society's constructions, preconceptions, and boundaries - all important perspectives to inhabit-a personal and very human understanding of the immigrant Latinas' responses to challenges can be gained through applying an existential psychology framework.

The paper is divided into five main parts following this introduction. Section 2 provides a brief overview of existential psychology and its grounding in the philosophy of existentialism. Two of the central concerns of existential psychology - free choice and meaningfulness - are highlighted. The following section explains the study's interview and qualitative analysis methodology. Section 4 explores what the interviews reveal about the Latinas' reasons for migrating and challenges they encountered after their arrival in Spain. Section 5 focuses on how the existential psychology perspective serves to inform our understanding of the immigrant Latinas' experiences. The section addresses the Latinas' responses to the challenges they encountered, interpreted in light of the meanings and sense of purpose they created in their situations. Section 6 provides a conclusion to the paper.

\section{Existential psychology}

Existential psychology is an outgrowth of the philosophy of existentialism as expounded in the writings of philosophers including Soren Kierkegaard (2004), Friedrich Nietzsche (1999), Martin Heidegger (2008), and especially John Paul Sartre (1975, 1993). Though existentialism is often thought to be an atheistic philosophy, there have been several outstanding examples of existentialists who were followers of one faith or another, including Gabriel Marcel (1984), Paul Tillich (2008), and Martin Buber (2000).

The fundamental claim of existentialism is that for human beings, existence precedes essence (Sartre, 1975). This dictum means that unlike other creatures and objects, whose essence is predetermined at the moment they come into existence, the essence of a human being cannot be defined prior to his or her birth. People are exceptions who are able to determine their essence by their choices. At each moment, they are free to choose who they will be and their purposes in life. Those choices, of course, are not made in a vacuum. The natural world, the social world, and physical constitution limit the choices people are able to make at any juncture. Yet, no matter what their situation may be, they are still able to choose what they will be and do within that situation. There is, in fact, no way to escape the freedom to choose who they will be according to existentialism. In Sartre's (1975) words, human beings are "condemned to be free."

Existential psychology is rooted in the philosophy of existentialism. Main expositors of existential psychology include Rollo May (1969), Viktor Frankl (2006), and Irvin Yalom (1980). There are several schools of this branch of psychology and therapy, but all take key tenets from existentialism. These include the principle that each person is self-created by freely choosing and actively pursuing the projects and purposes he or she chooses (Corey, 2017). These choices and the aims people follow often vary over time as they create and then re-create themselves again and again through the decisions they make. By doing so, they can also give rise to meaning in their lives, which is another central tenet of existential psychology.

The existential psychologist's emphasis on creating meaning through free choice is well represented by the quote, "He who has a why to live for can bear with almost any how," a statement attributed to Friedrich Nietzsche by Viktor Frankl (2006, p. 104). Frankl holds that 
humans possess a will to meaning. Through his work as a psychiatrist and experience as a Holocaust survivor, he determined that there can be meaning in life under all circumstances if we so choose. In his book Man's Search for Meaning, he argues that fully realizing our freedom to choose at every moment can foster our ability to embrace everyday life and find meaning in the suffering that we may encounter in living. The life meaning people create through their free choices is a central human need and considered to be one of the building blocks of well-being (Heintzelman \& King, 2014; Seligman, 2018; Steger, Oishi, \& Kashdan, 2009). We may find meaning in our relations to family and friends, our work, or any of countless other projects that engage our efforts. It is through extending those efforts toward the people and projects we consider important that we create the significance for which we have a natural hunger.

Like existentialist philosophers, existential psychologists emphasize that in creating meanings, people are making free choices - no matter what circumstances in which they may be embedded. In any situation, there will be circumstances that limit the actions the doer is able to perform; yet, within those limitations, the choice of what to do is free. A simple example: a mother desires to purchase a birthday present that expresses her caring for her daughter, but she is limited by very little money available. As a result, she freely resolves to seek out or create an appropriate present within her budget and does so. Making and acting on that choice infuses the mother's life with meaning and purpose.

These two central concepts that permeate the existential psychology viewpointmeaning and free choice - are thus related in the following way: the meanings of our lives are determined not externally, but by our choices. It is not culture, society, or personal circumstances that determine the meaningfulness in people's lives. It is they alone. Again, circumstances may be limiting, but within those circumstances people can always choose freely-as Frankl freely chose to find meaning and live meaningfully even within the horrible conditions of the concentration camp. While existential psychologists also interpret experience in terms of other concepts, such as existential anxiety and self-awareness, this paper is primarily concerned with their attention to the concepts of free choice and meaning. Given that focus, questions of intense interest to the existential psychologist when seeing a client may include, "What gives your life meaning and purpose?" "Who do you feel you are?" "What limitations or constraints do you encounter?" "Given those limitations, who do your freely choose to be, what purposes in life do you choose to pursue?"

\section{Method}

Purposeful sampling (Patton, 2002) was used to construct a sample of migrant Latinas who were pregnant or had given birth in Spain. Study participants came from three social service organizations where immigrant women who were pregnant or new mothers congregated. These organizations were located in three cities-Oviedo, Gijon, and Aviles. After being provided with an informed consent process including information about the nature and purpose of the study, a guarantee of anonymity, and assurance that they could withdraw from the interview at any time, 13 Latinas (median age 27) who had immigrated from six different Latin American countries consented to be interviewed. The semi-structured interviews lasted from 30 to 45 minutes and were audio-recorded, with participants orally answering the same questions asked by the researcher from a prepared questionnaire.

The interviews were transcribed into hard copy format, and a qualitative thematic analysis was conducted to determine codes and themes that were reflected in the responses of the participants. The researcher undertook three to four coding reviews of each interview, using an inductive, bottom-up analysis rather than codes being predetermined by the results of prior research or theory (Creswell \& Plano Clark, 2007). Codes were then examined together to determine categories or themes that they revealed. This process, too, took several iterations to 
complete. Based on the codes, eight themes were identified in the Latinas' responses to questions. Four of the themes are especially relevant to this paper's focus on how the migrant women's reported experiences can be interpreted in the light of existential psychology. These themes are Reasons for Deciding to Migrate, Challenges in Asturias, Roles of the Immigrant Mother, and Determination to Move Forward.

\section{Reasons for migrating and post-immigration challenges}

Before explaining how an existential psychology framework can be of value in understanding the reported experiences of the interviewed Latina immigrants, it is necessary to become familiar with some of those experiences. The interviewees' responses are reflected in the two themes of Reasons for Deciding to Migrate and Challenges in Asturias. Relevant comments by the Latinas are included below, with the interview participants identified by numbers 1 to 13 .

\section{Reasons for migrating}

One of the first questions asked of the Latinas was why they had immigrated to Spain. Their responses indicated they had varying reasons for migrating. For instance, Participant 7 (L7) explained that she had multiple rationales for migrating, including Spain's having a better economy than her country of origin, as well as less crime and better educational opportunities for her children.

Interviewer: Why did you come to Spain?

L7: I came looking for a different lifestyle, another type of economy. My country does not have it. Here at least I have another life. In my country there is a lot of crime. Having children over there is a problem. Here they can choose different habits depending on the education you give them; but in my country, it does not matter how much education you give them, sometimes they turn and take a different route. I decided to stay here with them because I had two children here. One is ten years old and the girl is eight. Here the education is different with respect to my country.

Participant 2 also mentioned crime in her former country as a reason for her having immigrated, along with the fact that she already had family members in Spain. Asked why she had immigrated, she replied:

L2: Because I have family here, and the situation in Peru is not all that good. There's a lot of crime and my sisters did not want to see me involved in any of that. For that reason, I left for Galicia.

Participant 12 offered that her reasons for immigrating were connected to a problematic relationship in her home country with the father of her child. At the time of the interview, the child was one month old.

L12: Four months into my pregnancy I talked to my friend, the one I mentioned before, and she convinced me to get out of the complicated situation I was in in Peru. My family accepted my decision. I arrived in Asturias on March 11th of this year.

Several other reasons for immigrating to Spain were also reported by the Latinas. These included coming to join family members who were already in Spain and coming as a student and then staying. 


\section{Personal challenges}

The interviewed Latinas mentioned a number of difficulties they had faced in Spain following their migration. These included personal, economic, and social challenges. One of the most prevalent personal challenges was that of being a single mother, without substantial assistance from the biological father of her child or children. Only two of the Latinas were living with the father of their child or expected child. Participant 12 made clear that she often found it difficult to be a single mother alone in Asturias.

L12: Generally speaking, I do think these things are much more difficult for a woman than they are for a man because the pregnancy is very difficult and everything that comes afterwards is also very complicated.... I am alone and for me a lot of times it is difficult. I have to take care of everything myself.

Participant 8 was also without her baby's father. She revealed that he had left them eight days after the child was born. She continued:

L8: He, my ex-partner, put in the divorce petition and we separated. The baby has fourteen months without seeing his father. He does not know his father, and it hurts very much because his first word was "dad." When mine or my mother's cellphone rings, the baby says "dad" and it hurts me.

Participant 4 was another Latina who was caring for her child without the aid of the father. When asked if the father was Spanish, she replied:

No, he was Colombian. I did not know he was older. I met him at a party, and we started dating. Further along when I got pregnant, I found out how old he was and that he had a family in Colombia. That was very hurtful but there was nothing I could do.

Some of the interviewed Latinas had help with their child from a family member, usually a mother, sister, or in-laws. Others did not. These included four who were living in a shelter at the time of the interview.

\section{Economic challenges}

Most of the interviewed Latinas faced economic difficulties. This was true of all the women living in a shelter, but also of several who were living with a relative. Participant 13 , who lived with her mother and daughter, spoke of the difficulty of working in Spain without documentation.

L13: Living here is complicated. Work is a difficult subject and also to obtain documents. My daughter does not have a passport, only her birth certificate.

This interviewee was unable to receive any public assistance due to her lack of documentation. When the researcher asked if someone other than her mother helped her, she replied:

L13: No. I asked for help, but they will not give me any because I do not have documents.

However, even without documents, this Latina revealed that she had found a job caring for children. She also reported that though she was estranged from the father of her child, who remained in her former country, he sent her money for the child. 
Participant 8, when asked whether her former partner helped with money or in some other way, responded:

L8: No. I look for a way. I don't have a stable job; I don't have a steady income ... I have to find my way in life ... He gives me 150 euros, which is what the divorce settlement stipulated. He thinks the baby eats from the air because 150 a month is nothing. The baby's food, diapers, and those things - that money is not enough for everything.

\section{Racism and stereotyping}

Another problem several of the Latinas had encountered was being subject to racism and stereotyping. When the interviewer asked Participant 10 whether she believed there were stereotypes of Latin American women in Asturias, she remarked:

L10: Yes, many think we came to take advantage of them. Others insult you directly, and others take advantage of you and when they don't need you anymore, they ignore you. However, there are also very nice people, although I was not fortunate to find many.

Participant 11 spoke of discrimination she had experienced.

L11: Yes, I have heard insults and things like that. There are racist people. Not that long ago I was at a bus stop and there were some guys who were passing out tickets to go eat at a pizzeria. The guys who were passing those things were only doing it among Spanish folks. I was there and they did not give me anything, but I don't care either.

Participant 1 believed that racism exhibited by her mother-in-law had been a cause of her husband leaving her. She said:

L1: He's Spaniard and his mother would tell him I was going to take advantage of him because I was foreign ... It's because the people from here are very racist. They see you are not from here and they won't accept you.

The Latinas' responses to questions about racism suggested that those with darker skin pigmentation were more likely to experience racism than those whose skin was lighter. Participant 13 remarked:

L13: What I see here, is that people are very racist. Here, I've had to do long lines at the bank while being pregnant ... In my country, priority is given to those pregnant. Spaniards see us as blacks coming to invade their country.

Participant 9 reported that she had not experienced any racist attitudes since immigrating and conjectured that the reason might be her skin pigmentation. When asked if she felt that people have stereotypes of Latin American women, she responded:

L9: In reality I don't know. I've only been here for a year and I have not seen any push back on Latin American women. I have not had any problems. Maybe it has not occurred because of my skin complexion. If my features were more of those similar to what normally is associated with my country, maybe I would have been rejected. 


\section{Viewing the Latina immigrants from an existential psychology perspective}

The existential psychology framework helps elucidate the interviewed Latina immigrants' migration decisions and their reported post-immigration challenges from a personal psychology standpoint. The Latinas' act of immigrating, their post-migration experiences, and their continuing to remain in Spain in the face of difficulties can all be understood in terms of the key existential psychology concepts of meaning, purpose, and free choice.

\section{The act of migrating}

The existential psychology emphasis on freely choosing actions for the sake of generating meaningfulness suggests that for each of these Latinas, her choosing to migrate to Spain and then actually doing so constituted her attempt to create new meanings in her life.

The choice to immigrate may have been anything but obvious to these women at first, and there may have been a back and forth mental struggle before the decision was made. It is reasonable to think that in contemplating the possibility of migrating to a new country, many or perhaps all of the interviewees anticipated that there were risks to doing so and that she might face challenges and perhaps hardships. There was also the prospect of having to leave behind an environment that was known to her, including family members and friends. Yet, she also likely considered that there were risks for staying in her original country. This is reflected in the previously noted responses of three of the women. Two referred to the amount of crime in their country of origin, which was a threat to peace of mind at the minimum, one spoke of leaving a problematic relationship, and another suggested that staying in her origin country may have placed her children at risk.

It is likely that what further-and perhaps mainly-entered into the Latinas' deliberations was the lure of the new country and migration's possibility of bringing her into a new relation with her future. Finally, each of the Latina immigrants decided that the promise of new meanings to be created in Spain was greater than the promise for her in the old country. She apparently judged that any psychological suffering that might result from leaving a familiar locale and migrating to a new one would be worthwhile if it brought new possibilities for independence, work, family, or economic well-being.

The action of leaving the home country and setting forth to a new land took courage. According to existential thought of May (1994), our choices determine the kind of person we become, and it takes courage to choose to be fully ourselves. The process of growth is a struggle within each of us, as expansion is painful. Maddi (2004) agrees with May, holding that people are always faced with the choice of either stepping into the future or staying in what may seem to be the safety of the past, with the choice to move into the future creating anxiety that requires existential courage to surmount. While the Latinas' living within the security of what they already knew may have been comfortable in some respects and therefore tempting, they evidently felt called toward new environments and ways of being even though largely unknown and unpredictable. Like all migrants, they chose the future and acted on that choice, demonstrating their courage.

\section{Post-migration Meaning and Purpose among the Immigrant Latinas}

It is notable that though the Latinas encountered various challenges after migrating to Spain, none of them had returned to her original country for anything more than a visit; nor did any speak of any intention or wish to return. These facts suggest that despite their challenges, the Latinas believed they had made the correct decision in immigrating. Thus, we can ask what factors helped consolidate these women's continuing choice to stay in Spain? 
From an existential psychology standpoint, one factor that may have contributed to the Latinas' decisions to stay in Spain was that despite the obstacles, they experienced substantial positive meaning in their lives in their new home. To better understand that possible factor, it helps to look more closely at the concept of meaning. When used to refer to the meaningfulness of people's lives and experiences, the term meaning has historically had various definitions; however, over time, the concept has become better understood. Today, the definition that arguably captures the core sense of the word as it is used in a construction such as "what gives my life meaning" is one that specifies meaning as having three dimensions: coherence, purpose, and significance (Heintzelman \& King, 2014; Park \& George, 2013). Combining these three dimensions, we may say that something has meaning for a person if it helps that individual make cognitive sense of his or her life, results in motivation to perform activities directed toward achieving certain goals, and provides the person with the sense that his or her life is of value (Martela \& Steger, 2016).

To the extent that the interviewed Latinas experienced positive meanings that provided their lives with coherence, purpose, and perceived value after immigrating, we should expect that they benefitted. This expectation follows from the premise that experiencing positive meaning in life is a main component of well-being (Pezirkianidis, Stalikasa, Efstathioua, \& Karakasidoua, 2016), which is a premise supported by studies finding that people's sense that their lives have meaning is related to their psychological well-being (Dezutter, Casalin, Wachholtz, Luyckx, Hekking, \& Vandewiele, 2013; Garcia-Alandete, 2015). Various other positive outcomes have also been associated with experiencing positive life meaning, including life satisfaction, satisfaction with self, ego resilience, and environmental mastery (Steger, 2012). These research findings strongly suggest that to the extent that the Latinas experienced positive meanings in their lives post-migration, they also enjoyed an increase in their strength and resilience in the face of difficulties and affirmed their decision to migrate to a society that offered greater safety and potential opportunities than the one left behind.

And indeed, there is evidence that in Spain, most of the migrant Latinas found powerful meanings that gave them a sense of coherence, purpose, and significance in their lives and helped them deal with post-migration challenges. Given the women's interview responses, two kinds of life meanings that they experienced are evident. The first, and clearly a powerful one for the women, was the simple fact of Being a Mother. This was an identity that characterized all of the Latina immigrants in their present or near future Two had arrived in Spain with children and then had given birth to a child after immigrating. Nine had given birth only after they had immigrated to Spain. Two were pregnant and well on their way to becoming a firsttime mother in their new country. Given that role identity is positively associated with acquiring role-related meaning and purpose (Thoits, 2012; Waterman, 1984), the immigrant Latinas' filling the role of being a mother created life meaning for them.

This can be seen in the Latinas' words, as repeatedly, their interview responses told the story of how their mothering a child or the prospect of mothering a child provided powerful meaning in their lives. For instance, Participant 7's dedication to her two children, a girl eight and a boy ten, is evident from her words:

L7: There are a lot of mothers [in Spain] that are worried for their children, they give everything for them. In my country as well. Fathers will leave, and they [mothers] will move forward with their children, because we never stop being a mother and children never stop loving. ... You have to teach your children values so they can learn and so they can be whatever they want, so they don't have to dedicate themselves to cleaning like I do. They, my children, ask me for things and 
I try very hard to give it to them, but I ask them to comply with their obligations.

Those are the values we must teach our children.

In this response, the Latina suggests that she, like many mothers, is devoted to her children and will do whatever is in her power toward ensuring their well-being. She views herself as a mother who loves her children and tries to provide them with whatever they ask for so they will have greater opportunities than she has had. Her words clearly suggest that caring for her children provides her life with a sense of purpose and significance.

Participant 2, a mother of three, spoke of her love for her children and of the great responsibility she felt in raising them. Her words gave evidence of the meaning and purpose being a mother gave to her.

L2: The teachers [at the school] tell me I am very lovable with my children when I say goodbye to them. I always kiss them, wish them a good day and give them their blessing. The other parents don't do the same. ... I knew having children at 20 years old would be a great responsibility, but I thought if I was pregnant it must be for a reason. I never thought about having an abortion.

The meaning being a mother gave to her life was also evident for Participant 8 when she was asked whether, during her pregnancy, she always knew she would have her 14-monthold son.

L8: Yes, I did not doubt it. Since I found out I was pregnant I looked forward to it.... I decided to have my first child and I'm very happy, thank God. If I would have had an abortion, I would have regretted it my entire life. .... People would say I was very young. When I got pregnant, I was almost 19 years old, but I always took pride in being a young mother. ... I am young, but I educate my son how my parents educated me.

In reply to the question of what she considered being a good mother, Participant 13, mother of a five-month-old girl, gave testimony to how much meaning and purpose being a mother gave to her life by remarking on her willingness to do any sort of work to earn income so she could care for her daughter.

L13: It's also important to do anything for your children. If I have to clean the streets to take care of my daughter, I will do it, but there are mothers who have issues if they had to do those things.

Participant 12, who had a one-month-old son, was asked how she had felt emotionally over recent months.

L12: Before giving birth, I was very depressed. Sometimes I would ask myself what was I doing here. After giving birth things changed. It was like a blessing. I don't feel alone because I have my son, which taking care of him takes a lot of time. I still miss my family, but I don't feel that loneliness I felt before.

The Latina immigrants made other remarks that reflected the powerful meaning that being a mother had for them. Examples follow.

L3 (baby son): Yes, for me my son comes first. 
L4 (daughter about five years old): On one side I have my family, my family is my mother and my daughter. I know that before me there is them. To see my mother and my daughter happy, makes me happy.

L5 (daughter one month old): A mother is everything. The men are dedicated to work and $a$ mother always takes care....

L6 (five months pregnant and a son seven years old): I believe they [Spanish mothers] take everything more relaxed. We are a lot more dedicated to our children.

L9 (22 weeks pregnant): What I see is that we have a great responsibility and blessing, which is to bring life to this world.

L10 (son, three and a half years: I think that my child comes first....

L11 (daughter three years old): I love my daughter more than anything in this world...

These remarks indicate that for most if not all of the immigrant Latinas, being a mother gave great meaning to their lives. Given the tripartite definition of life meaning as consisting of coherence, purpose, and significance, it is probable that the powerful meaning of being a mother helped the Latinas deal with their post-migration life in several ways. First, it likely helped them make sense of their lives in Spain by establishing the mothering role as part of their selfperceived identity. It also helped structure their lives by giving them a major goal to pursuethe well-being of their child or children - thereby creating short- and long-term purposes. Third, it instilled a sense of their personal significance and value as they knew they were in charge of what many would argue is a most important human project — raising a child. It seems likely that these outcomes of finding meaning in being a mother confirmed the women in their decision to migrate and strengthened them as they encountered post-immigration challenges.

The Latinas' interview responses gave evidence that they experienced a second kind of life meaning that provided them with coherence, purpose, and significance. This was their Determination to Move forward. The resolve to move "forward" or "ahead" (adalante) was explicitly stated by many of the women and implicitly referred to by others, suggesting it as a way they self-identified and as an overall goal that gave their lives meaning. The goal was often mentioned in conjunction with their identity as a mother, indicating that a major reason they were moving forward was for their child or children. In these cases, the two life meanings of moving forward and being a mother intersected. In other cases, the sense of a Latina's words indicated that her moving forward was a determination that included advancing the lives of her children but also advancing her own independence and success.

An instance of the first kind of remark, which referred to moving forward with her child or children, was a comment by Participant 11, who spoke of her determination to move forward despite difficulties.

L11: I want to think it's not difficult, because if I did, it's like thinking it couldn't get better. I think that although it's not easy, I am able to move forward with my daughter. I try not to focus on how difficult it can be, but to cheer me up so I can give my daughter an education and both of us move forward.

This Latina's resolve was further reflected in her response to the question of why she had decided to have her baby. 
L11: Although I knew it would cost me to move forward with my baby, I decided to have her because I wanted to see her grow and I knew I would make it.

Participant 6 spoke of becoming more independent from her mother and having found a job as a way of moving forward with her daughter.

L6: I moved because my mother would not let me be a mother. I am now independent and have a job. I continue to move forward with my daughter by myself.

Later, her words reflected her determination to remain in Spain so her daughters would be able to enjoy the greater opportunities that Spain provided.

L6: I would always see myself older returning to the Dominican Republic, living in a wooden home, but not anymore. I have two daughters and I know they can have better opportunities here.

Her resoluteness in making a life for herself and her daughters was further expressed in her response to being questioned whether she felt there were barriers to finding work in Spain.

L6: No. I studied at the E.S.O and after that I completed a program for administration. At the same time, I would go to school and work at a pizzeria. Since then I have worked at jewelry stores, bars, and so on .... This pregnancy is going a lot better and I am still willing to do courses and maintain myself active.

Participant 7, in response to the question of whether her pregnancy had been comfortable, remarked that though it had been mentally distressing due to absence of her partner, she had been able to move forward.

L7: I did not have a high-risk pregnancy or none of that, but psychologically I was not good. Being alone was traumatizing me, being here alone with a small child and pregnant, but thank God I was able to move forward.

Later in her interview, this Latina mentioned the work she was willing to perform to supplement public assistance and move forward with her children.

L7: I get help from the social unemployment. They give me 641 euros every month. With that I try to move forward. If someone calls me for cleaning, I will do it. I try to move forward with my children, because with 641 Euros you can't make it.

When asked whether she was working now, Participant 4 spoke of her resolution to find a new job so that she could take care of her daughter.

L4: Not now. I was working up until three days ago; the lady I was taking care of passed away. I now have to look for another job to continue to take care of my daughter.

Other comments by the immigrant Latinas expressed their belief that they were growing and the confidence they had in themselves, again strongly suggesting their commitment to positively moving ahead as immigrants in Spain.

L12: On occasions I get frustrated because I want to do everything right, but I don't have help from anyone. I know that if my mother would be with me, she would help me a lot. I think that going through this situation alone is also helping me; it's helping me grow. 
L8: Thank God I am a healthy girl. I have never fallen into bad habits, I'm smart. I have my education and I have managed to keep going, I have been able to do everything.

L8: I don't have a stable job; I don't have a steady income. I have to find my way in life. My mother sometimes helps me with what she can and I look for work too, whatever; clean plates, clean houses, clean the elderly, I don't care, whatever comes up. Right now, I am looking for work although it's not permanent, and that is my life. It's been hard but I continue ahead. I have gotten ahead and continue to come out with my head held high and I'm not ashamed of anything.

Two of the Latinas spoke eloquently about their striving for a life that did not totally revolve around her children. Participant 9, who was in school, told of her resolve to have a career in Spain and a degree of independence that would be more difficult to achieve in her original country.

L9: Ifeel blessed. Ifeel things happened this way, because this is the way they were meant to be. ... Here I will fight to continue with my career. ... In Latin America a mother has to always be at home with their children. Here things are different. Women are more independent.... Many don't have kids past 30. Many have children, but that does not mean they have to give up their career. I am Peruvian, but I don't believe my life has to be only around my children. I would like to be working and going to school too.

Participant 3 was another immigrant Latina who was working for a better future by going to school. Her words suggested that she believed being a mother was compatible with having some independence:

L3: Now that I'm in school I take the baby to daycare. Sometimes my grandmother or godmother will also take care of him, especially when I have homework related to school.

Based on these comments, a picture emerges of strong women who are determined to make a life in Spain for themselves and their children. Only one of the Latina immigrants, Participant 10, seemed to have a somewhat downcast view of the future.

L10: I see the future very dark because if I don't find a job, I don't know what we will do to move ahead.

However, another response by this Latina suggested that she was determined to stay in Spain for the sake of raising her daughter.

L10: If I had a father and mother I would be very well spiritually, but I will also tell you it is very difficult to raise a child in Brazil. There is a lot of crime and insecurity. Here, education is very good and opens a lot of doors. Here there are also a lot of bad people, but there are more opportunities.

In sum, the Latina immigrants gave strong evidence through their comments that they found meanings in Asturias that provided their lives with coherence, purpose, and significance. In particular, these women found meaning in their identity as mothers and in their determination to overcome obstacles and move forward for the sake of their children and their own future. It is probable that these meanings provided strength and resilience as the women encountered challenges and that they helped confirm their decision to stay in Spain. Evidently, the courage 
and striving toward the future that these women displayed by immigrating from their home country to Spain still characterized them at the time of their interview.

\section{Conclusion}

The decision of the Latina immigrants in this study to venture forth from their country of origin and migrate to Spain can be examined from various standpoints. Approaches include taking into account social circumstances within the countries of origin and destination, relevant historical and political realities, and global immigration movements. There is no doubt that all of these perspectives can be valuable in helping to understand factors that influenced these women's immigration to Spain and their post-migration experiences. Indeed, several of the interviewed Latinas reported that the social realities of a greater extent of crime in their country of origin or a lesser degree of economic opportunity were factors they considered in deciding to migrate to Spain.

However, one may question why these particular Latinas decided to leave their country of origin when the great majority of their fellow citizens did not, though those others also faced the same social realities. To address this question, one may seek explanations that attempt to view the Latinas in terms of their personal attributes and purposes. An examination from the standpoint of existential psychology's emphasis on free choice and meaning as key concepts for understanding people and their activities provides such a personal way of examining why the Latinas migrated to Spain. This paper presents an explanation by focusing on how these women's migration can be understood in terms of their having chosen to create new meanings in their lives and having the courage to put their choice into action.

One may also ask what personal factors helped the immigrant Latinas deal with economic, social, and personal challenges they faced after immigration. What enabled them to weather those difficulties and continue to choose to remain in their new country? Again, an explanation in terms of existential psychology's close attention to free choice and meaning can be valuable. By their comments, the women gave ample evidence that their self-identification of being a mother pervaded their lives with meaning. Caring for their children likely helped them make sense of their lives in Spain, provided them with important purposes, and gave their activities perceived significance. The women also made clear in their comments that another important source of meaning in their lives was their determination to move forward for the sake of their children and their own future. The resolve of these women to make a life for themselves and their children in Spain gave their lives coherence, purpose, and felt value. It also gave evidence of their strength and tenacity. It has been pointed out that migrants bring many desirable characteristics with them, including courage, resilience, openness to new experience, willingness to take risks, and readiness to work hard (Adler \& Gielen, 2003). These qualities are clearly assets to their destination country. In the case of the Latina immigrants in this study, it is very likely that their chosen land of Spain will benefit from their decision to make it their new home.

\section{REFERENCES}

Adler, L. L., \& Gielen, U. P. (2003). Preface. In L. L. Adler \& U. P. Gielen, Migration: Immigration and emigration in international perspective (pp. xii-Xv). Westport, CT: Praeger.

Buber, M. (2000). I and thou. New York, NY: Scribner.

Corey, G. (2017). Theory and practice of counseling and psychotherapy (10th ed.). Boston, MA: Cengage Learning.

Creswell, J.W., \& Plano Clark, V.L. (2007). Designing and conducting mixed methods research. Thousand Oaks, CA: Sage Publications.

Dezutter, J., Casalin, S., Wachholtz, A., Luyckx, K., Hekking, J., \& Vandewiele, W. (2013). Meaning in life: An 
important factor for the psychological well-being of chronically ill patients? Rehabilitation Psychology, 58(4), 334-341. DOI: 10.1037/a0034393

Frankl, V. E. (2006). Man's search for meaning. Boston, MA: Beacon Press.

Garcia-Alandete, J. (2015). Does meaning in life predict psychological well-being? An analysis using the Spanish versions of the Purpose-In-Life Test and the Ryff's Scales. The European Journal of Counselling Psychology, 3(2), 89-98. DOI: 10.5964/ejcop.v3i2.27

Heidegger, M. (2008). Being and Time. New York, NY: Harper and Row.

Heintzelman, S. J., \& King, L. A. (2014). (The feeling of) Meaning-as-information. Personality and Social Psychology Review, 18, 153-167. DOI: 10.1177/1088868313518487

Kierkegaard, S. (2004). Either/Or, A Fragment of Life. London: Penguin Group.

Maddi, S. R. (2004). Hardiness: An operationalization of existential courage. Journal of Humanistic Psychology, 44(3), 279-298. DOI: 10.1177/0022167804266101

Marcel, G. (1984). The philosophy of existentialism. New York, NY: Citadel Press.

Martela, F., \& Steger, M. F. (2016) The three meanings of meaning in life: Distinguishing coherence, purpose, and significance. The Journal of Positive Psychology, 11(5), 531-545. DOI: $10.1080 / 17439760.2015 .1137623$

May, R. (1994). The courage to create. New York, NY: W. W. Norton \& Company.

May, R. (1969). Existential psychology. New York, NY: Random House.

Nietzsche, F. (1999). Thus spoke Zarathustra. Mineola, NY: Dover Publications.

Park, C. L., \& George, L. S. (2013). Assessing meaning and meaning making in the context of stressful life events: Measurement tools and approaches. The Journal of Positive Psychology, 8(6), 483-504. DOI: $10.1080 / 17439760.2013 .830762$

Patton, M. Q. (2002). Qualitative research and evaluation methods (3rd ed.). Thousand Oaks, CA: Sage.

Pezirkianidis, C., Stalikasa, A., Efstathioua, E., \& Karakasidoua, E. (2016). The relationship between meaning in life, emotions and psychological illness: The moderating role of the effects of the economic crisis. The European Journal of Counselling Psychology, 4(1), 77-100. DOI: 10.5964/ejcop.v4i1.75

Sartre, J-P. (1993). Being and nothingness. New York, NY: Washington Square.

Sartre, J-P. (1975). "Existentialism is a humanism." In W. Kaufmann (Ed.), Existentialism from Dostoevsky to Sartre (Rev. ed.) (pp. 345-368). New York, NY: Penguin Group.

Seligman, M. (2018). PERMA and the building blocks of well-being. The Journal of Positive Psychology, 13(4), 333-335. DOI: 10.1080/17439760.2018.1437466

Steger, M. F. (2012). Experiencing meaning in life: Optimal functioning at the nexus of well-being, psychopathology, and spirituality. In P. T. P. Wong, The human quest for meaning: Theories, research, and applications (2nd ed.) (pp. 165-184). New York, NY: Routledge.

Steger, M. F., Oishi, S., \& Kashdan, T. B. (2009). Meaning in life across the life span: Levels and correlates of meaning in life from emerging adulthood to older adulthood. The Journal of Positive Psychology, 4(1), 43-52. DOI: $10.1080 / 17439760802303127$

Thoits, P. A. (2012). Role-identity salience, purpose and meaning in life, and well-being among volunteers. Social Psychology Quarterly, 75(4), 360-374. DOI: 10.1177/0190272512459662

Tillich, P. (1952). The courage to be. New Haven, CT: Yale University Press.

Yallom, I. (1980). Existential psychotherapy. New York, NY: Basic Books. 